\title{
A New Case of Ants Nesting within Branches of a Fig Tree: the Case of Ficus subpisocarpa in Taiwan
}

by

A. Bain ${ }^{1,2}$, B. Chantarasuwan ${ }^{3}$, L.S. Chou ${ }^{1}$, M. Hossaert $\mathrm{McKey}^{2}$, B. Schatz ${ }^{2}$ \& F. Kjellberg ${ }^{2 *}$

\section{ABSTRACT}

Ficus is one of many plant genera involved in interactions with ants. The interaction is however little documented. We show here that ants, belonging mainly to the genus Crematogaster, nest in hollow internodes of young branches of Ficus subpisocarpa, a monoecious fig species studied in Taiwan. The ants feed on the mutualistic fig-pollinating wasps as well as on parasitic non-pollinatingfig wasps. Nevertheless fig-wasps may not constitute a sufficient food source to ensure permanent presence of ants on the tree as the ants were observed to be frequently associated with hemipterans such as coccids and aphids. Fig wasps seem to constitute a reliable and sufficient food source on some dioecious Ficus species. On the contrary, in monoecious Ficus species, resident ants have always been observed to tend homopteran in addition to feeding on fig wasps. Frequent fruiting, prolonged fruit ripening period, ramiflory and rapid growth could constitute traits facilitating strong association based on fig-wasps' consumption of the monoecious F. subpisocarpa with ants. Despite these traits, ants were observed to tend hemipterans, and $F$. subpisocarpa does not seem to have evolved specialized morphological traits to facilitate the association.

Key words: ant-plant interaction, community ecology, Asian biodiversity, myrmecophytism, ant foraging.

\footnotetext{
${ }^{1}$ Institute of Ecology and Evolutionary Biology, College of Life Sciences, National Taiwan University, 1, Sec. 4, Roosevelt Rd., Taipei, 10617 Taiwan.

${ }^{2}$ Centre d'Ecologie Fonctionnelle et Evolutive CEFE, UMR 5175 CNRS, 1919 route de Mende, 34293 Montpellier France

${ }^{3}$ Netherlands Centre for Biodiversity Naturalis (section NHN), Leiden University, P.O. Box 9514, 2300 RA Leiden, The Netherlands and Thailand Natural History Museum, National Science Museum, Pathum Thani, 12120, Thailand.

*Correspondence: finn.kjellberg@cefe.cnrs.fr
} 


\section{INTRODUCTION}

A major challenge of ecology is the assessment of species' communities and the understanding of the determinants of their structure and organization (Fortuna \& Bascompte 2006; Bascompte \& Jordano 2007; Proffit et al. 2007; Bascompte 2009; Cavender-Bares et al. 2009; Ings et al. 2009; Vázquez et al. 2009). Various groups of insects have inspired the development of theories in community ecology. They have long been recognized as convenient models for testing hypotheses in this domain (Heil \& McKey 2003). Among them, ants (Hymenoptera: Formicidae) can be central for such perspectives, as they often play a major role in interaction networks as predators (Lach et al. 2009), seed dispersers (Giladi 2006), pollinators (Rico-Gray \& Oliveira 2007), mutualistic defenders of their host-plants (Heil \& McKey 2003; Heil 2007) and exploiters of various mutualisms (Schatz et al. 2006, 2008). More specifically, ants have been widely studied for their interactions with plants. Ant-plant protection mutualisms have been reported in 100 plant genera and 40 ant genera, mainly in tropical regions (Davidson \& McKey 1993; Speight et al. 2008). The high diversity of this type of interaction even within genus (Webber et al. 2007) is explained by easy development of mutualistic interactions. Indeed, the strong potential protection against herbivores provided by ant colonies may substantially increase plant fitness (Rosumek et al. 2009). Specialized ant-plant interactions have been used as ecological and evolutionary models to understand selective factors affecting plants (Heil \& McKey 2003). Some of these specialized interactions have been shown to be structured by chemical mediation (Ranganathan \& Borges 2009; Schatz et al. 2010) and support complex networks of plurispecific interactions involving herbivores, parasites, predators and secondary mutualists (Palmer et al. 2008; Schatz et al., 2008, 2010; Blatrix et al. 2009; Goheen \& Palmer 2010).

Among the numerous genera of plants associated with ants, the interaction between Ficus and ants has been poorly studied. Ficus is one of the 100 plant genera presenting what has been interpreted as structures specifically evolved to host ant nests (Speight et al.2008), with only a single case hitherto reported for this genus (Maschwitz et al. 1996). Figspecies are known for their obligate species-specific nursery pollination mutualisms with fig wasps (Janzen 1979; Kjellberg et al. 2005). Specificity is reinforced by a physical filter (matching 
between pollinator head shape and ostiole structure; van Noort \& Compton 1996) and chemical mediation (emission of volatile compounds responsible for pollinating wasp attraction by receptive figs; Grison et al. 1999; Proffit et al. 2007, 2008, Hossaert-McKey et al. 2010). Ficus are increasingly investigated for their role in supporting a complex network of interactions involving a community of species-specific parasitic chalcid wasps (regionally up to 25 parasitic species for a single Ficus species, Bouček et al. 1981), but also several species of ants, all of them capable of detecting and using chemical signals emitted by figs (Chen et al. 1999; Kjellberg et al. 2005; Proffit et al. 2007; Ranganathan et al. 2010; Schatz et al. 2008,2010). Within that network, ants have been shown to severely reduce the prevalence of parasites and to be a structuring factor for various other insect species (other predators, herbivores, visitors) (Schatz \& Hossaert-McKey 2003; Schatz et al. 2006, 2008, Wei et al. 2005). Ants have often been reported to be predators of fig wasps. They have also been observed to participate in fig-seed dispersion (Kaufmann et al. 1991; Roberts \& Heithaus 1986; Laman 1995, 1996) and they are involved in ant-homopteran-fig tree tritrophic interactions (Compton \& Robertson 1988, 1991; Dejean et al. 1997, Ranganathan et al. 2010).

Fig wasps may constitute a major source of food for ants. Indeed, Schatz et al. (2008) demonstrated on dioecious Ficus species that fig wasps on male trees provided a sufficiently abundant and reliable resource to allow continuous presence of dominant ants on the trees. However, whether fig wasps may constitute a sufficient resource in monoecious Ficus species is still an open question. Indeed, these species produce figs less frequently than dioecious ones and often present more synchronized crops (e.g. Shanahan et al. 2001). Hemipterans could constitute an alternative resource that could allow the continuous presence of tending ants on monoecious fig trees (Schatz et al. 2008). However, the presence of hemipterans and tending ants on monoecious fig species has been mainly reported from Africa and Madagascar ( $F$. sur in South Africa [Compton \& Robertson 1988, 1991; Zachariades 1994]; F. vallis-choudae in Cameroon [Dejean et al. 1997], and several fig species in Madagascar, Malawi, South Africa, Zambia, and Zimbabwe [Cushman et al. 1998]) while the most convincing data on fig wasps providing sufficient food for ants in dioecious figs stems from Borneo (Schatz et al. 2008). Hence, to confirm that continuous ant presence on monoecious fig trees is systematically 
associated with the presence of hemipterans, we need to record whether in other parts of the world, ants on monoecious Ficus are systematically associated with hemipterans.

For ants, a fig tree may constitute an appropriate support presenting dispersed feeding sites, located exclusively in the arboreal stratum. Optimization of fig wasp capture efficiency could lead ants to inhabit this stratum in order to reduce distance between their nest and this food source in accordance with central place foraging theory (Stephens \& Krebs 1986; Bell 1991; Schatz et al. 2008). Diverse reports of arboreal ant nests within fig trees support this hypothesis, and suggest that ants effectively find sufficient food sources within fig trees. Examples include nest location among the leaves of $F$. fistulosa for Oecophylla smaragdina and of F. sur for O. longinoda (Thomas 1988; Schatz et al. 2008), between grouped figs of the cauliflorous $F$. botryoides for unidentified Formicidae (Dalecky et al. 2003) and cauliflorous figs of $F$. fistulosa for Crematogaster sp. (Schatz et al. 2008), within figs of F. sycomorus by Cardiocondyla wroughtoni (Lupo \& Galil 1985), in large persistent stipules (up to $80 \times 20 \mathrm{~mm}$ ) of $F$. paracamptophylla often tenanted by ants (Corner 1976), in ant gardens on F.paraensis and F. trigona for Camponotus femoratus and Azteca cf. traili (Davidson 1988; Benzing 1991) and within the dead parts of branches on F. carica by Crematogaster scutellaris (Schatz \& Hossaert-McKey 2003). Moreover, one species of Ficus presents what appear to be structures specifically evolved to host ant nests (Maschwitz et al. 1996). This study showed that $64 \%$ of the opened structures they called domatia of Ficus obscura var. borneensis (included in Ficus pisifera sensu Berg \& Corner 2005) were inhabited by ants, belonging to eight species distributed into five genera (Camponotus, Cardiocondyla, Cataulacus, Crematogaster and Tetramorium). Despite lack of description of ant behavior on this species, the presence of extrafloral nectaries and structures sheltering opportunistic ants on F. obscura var. borneensis suggests existence of a non-specific protection mutualism. Interestingly, in their field survey, Maschwitz et al. failed to detect similar structures in Ficus species belonging to over 20 other Malaysian fig species and they also failed to detect such structures in a survey of herbarium samples from 37 Australasian fig species.

In this study conducted in the island of Taiwan, we focused on the monoecious Ficus subpisocarpa. We describe here the presence of hollow structures 
inhabited by ants in a fig tree associated with an plant-ant interaction. We determined the frequency of the hollow structures and the ant occupancy and we identified the observed ants to genus and describe traits of their presence. We also correlate ant presence and presence of hemipterans. We then discuss the insights into ant-fig interactions brought about by this discovery of a new case of ants inhabiting hollow structures in fig trees.

\section{MATERIALS \& METHODS}

Ficus subpisocarpa Gagnep. is a monoecious fig tree belonging to subsection Urostigma (sensu Berg \& Corner 2005). It is a hemiepyphitic or terrestrial tree which grows up to $7 \mathrm{~m}$ in height distributed in South Asia from the South of Japan to Taiwan and to the Malay Peninsula and the Maluku Islands (Berg and Corner 2005). This species produces abundant crops, 2-4 times per year, of small cauliflorous figs, ripening over a 1-3 week period (Corlett 2006; Bain pers.obs. for Taiwan). As most species of subsection Urostigma, F. subpisocarpa is a deciduous tree presenting rhythmic growth (Berg \& Corner 2005).

Hollowed stems hosting ants were incidentally noted on individual trees growing in Taiwan when inspecting trees for ant presence. To better describe and quantify this trait we examined branches from a series of individual trees. Branches were collected on eight trees: six in Taipei (National Taiwan University campus and Fuzhoushan Park), one $25 \mathrm{~km}$ north, at Bitou Cape on the North Coast of Taiwan and one $350 \mathrm{~km}$ south, in Kenting in the extreme south of the island. Five to 16 apical branches were sampled for each tree at their junction with a main trunk. Indeed such branches usually grow directly from the trunk or from main branches and usually wither without reaching more $60 \mathrm{~cm}$ (Bain pers. obs.).

For each branch we measured length, diameter of the branch at the cutting level, diameter at the middle of the apical internode and we counted the number of ramifications. Then the branches were split lengthwise, and the length of each hollow section (hereafter called cavity) was measured. Branch diameter was measured at the middle of the cavity as well as the distance from the branch apex.

When ants were observed in the cavity, the inner diameter of the cavity was measured and the number of exit holes noted. The cavities were characterized as described in Fig. 1 into six categories: young cavities empty or attacked 
by insect larvae, inhabited and previously inhabited cavities, mature cavities, and old cavities. The sequence of the cavities from the apex was noted and for trees 02, 03, 04 and 06, the precise internodes, numbered from the apex, where the structures were observed were also noted. The insect content of inhabited cavities was collected, identified and counted. Ants were identified to genus using Bolton (1994) and Lin \& Wu (2003).

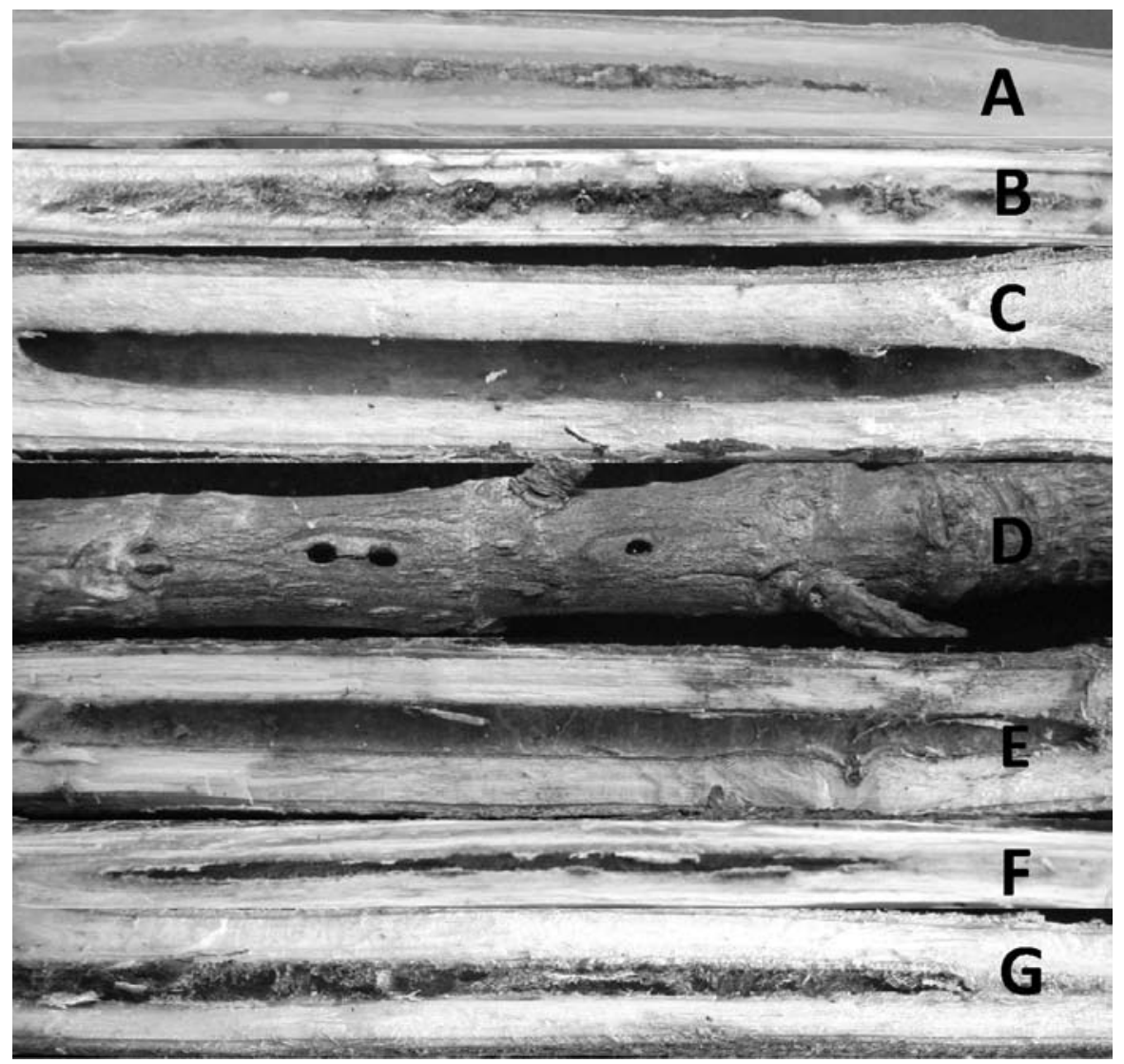

Fig. 1. The different types of cavities. A) Young cavity: these cavities are characterized by their young tissues. Only the central part is hollowed, the inner pith has not dried out yet. B) Young attacked cavity: the structure of the cavity is the same as for young cavities but insect larvae are feeding inside. C) Inhabited cavity: ants are observed inside. All pith tissue has been removed. D) Entry holes of an inhabited cavity. E) Formerly inhabited cavity: all the pith has been removed but no ant live inside. Often fungi or mould have grown on the inner surface. F) Mature cavity: the inner pith has dried out all along the internode. G) Old cavity: secondary growth is beginning to compress the cavity 
An additional set of trees were examined for the presence of ants and of hemipterans to determine whether there was a frequent association. One hundred ten branches distributed on 11 trees located in Taipei were examined.

Additionally herbarium samples originating from Japan, Vietnam and Thailand were examined for the presence of similar hollow structures. They included samples of Ficus subpisocarpa subpisocarpa, F. subpisocarpa pubipoda C.C. Berg and the closely related F. geniculata. The herbarium samples examined were:

Ficus subpisocarpa Gagnep., JAPAN: Kagoshima Pref., Yaku Is., 20 May 1984, T. Yahara, T. Nagamasu \& T. Kawahara 10340 (L); Ryukyu Islands, Misato-mura, Matsumo to-aza, 7 August 1951, E.H. Walker, S. Tawada, T. Amano 6441 (L); VIETNAM: Sai Wong Mo Shan (Sai Vong Mo Leng), Lomg Ngong Village, Dam-ha, Tonkin, July 18 - Sept 9, 1940, W.T. Tsang 30348 (L).

Ficus subpisocarpa Gagnep. subsp. pubipoda C.C. Berg. THAILAND: Ranong, Kaper, Laem Sohn National Park, sea level, 30 November 1996, J.F. Maxwell 96 - 1568 (L); Chiang Mai, Muang, Doi Sutep - Pui National Park, elevation 1350m, 26 March 2002, J.F. Maxwell 02 - 103 (L); Chaiyaphum, between Nam Phrom and Thungkamang, alt. 800m, 13 Dec 1971, C.F. van Beusekom, R. Geesink, C. Phengkhlai \& B. Wongwan 4218 (L).

Ficus geniculata Kurz. VIETNAM: Cana province de Phanrang, 25 Oct 1925, M. Poilane 12491 (P); Ka Rom pr. Phanrang, 7 Mar 1924, M. Poilane 9964 (P); THAILAND: Lampang, Jae Home, Doi Jae Sawn National Park, alt. 425 m, 7 Jan 1992, J.F. Maxwell 92 - 16 (E); Tak, Mueang, Rd. No. 105, km 19 - 20, alt. 400 m, 21 Nov 2005, R. Pooma, C.C. Berg \& M. Poopath $5734(\mathrm{~L})$.

\section{RESULTS}

\section{Occurrence of cavities}

Sampled branch length ranged from $21 \mathrm{~cm}$ to $156 \mathrm{~cm}$. Ten percent of the studied branches presented no cavity, $36 \%$ presented a single cavity and $54 \%$ presented several cavities (Table 1 ). The average length and diameter (at cutting level) of branches did not differ between branches with and without cavity (Mann-Whitney U test, NS). 
Table 1. Cavity data per tree. Cavity types are defined according to Fig. 1. The two undetermined cavities correspond to cavities that were damaged during sampling. All trees located in Taipei, except for Tree 7 located at Bitou Cape and Tree 8 located at Kenting.

\begin{tabular}{llllllllll}
\hline \hline & \multicolumn{7}{c}{ Tree } \\
& 1 & 2 & 3 & 4 & 5 & 6 & 7 & 8 & Proportion \\
\hline Number of branches & 13 & 10 & 10 & 16 & 12 & 10 & 10 & 5 & \\
Young healthy cavity & 11 & 6 & 4 & 3 & 4 & 3 & 3 & 1 & 0.172 \\
Young attacked cavity & 3 & 6 & 5 & 0 & 6 & 4 & 1 & 1 & 0.127 \\
Inhabited cavity & 3 & 4 & 0 & 0 & 16 & 7 & 1 & 1 & 0.152 \\
Formerly inhabited cavity & 0 & 0 & 0 & 1 & 9 & 1 & 1 & 0 & 0.059 \\
Mature unused cavity & 7 & 17 & 3 & 22 & 24 & 15 & 2 & 2 & 0.451 \\
Old cavity & 0 & 3 & 0 & 0 & 3 & 0 & 0 & 0 & 0.029 \\
Undetermined & 0 & 0 & 0 & 0 & 0 & 0 & 1 & 1 & 0.010 \\
Total & 24 & 36 & 12 & 26 & 61 & 30 & 9 & 6 & \\
\hline \hline
\end{tabular}

On the 86 analyzed branches, a total of 204 cavities were observed $(2.4 \pm$ 2.0 cavities per branch or $4.2 \pm 3.1$ cavities per meter). The number of cavities per branch varied significantly among trees from 0.90 to 5.0 (One-Way ANOVA $_{6,79}=11.85 ; p<0.001$ ) (Table 1 ).

\section{The different types of cavities}

We identified six kinds of cavities in F. subpisocarpa branches (Fig. 1): young cavities, intact or attacked by insect larvae, cavities inhabited by ants and cavities formerly inhabited by ants, mature cavities, old cavities. The most frequent hollow structures were mature cavities (45\%), followed by young cavities (30\%, 17\% intact and 13\% attacked by insect larvae) and inhabited cavities (15\%). Young and mature cavities were observed on all trees. Cavities inhabited by ants were observed in six of the trees (75\%), and a formerly inhabited cavity was observed on an additional tree. Two-third of the inhabited cavities sheltered ant pupae or larvae. Out of the 32 inhabited cavities, 7 were located on branches that presented a young cavity attacked by insect larvae (22\% of the inhabited cavities): protection, if any, is not perfect.

\section{Length of cavities}

The length of most cavities (75) ranged from 2 to $14 \mathrm{~cm}$ (Fig. 2). Four cavities measured less than $2 \mathrm{~cm}$ and seven were longer than $22 \mathrm{~cm}$. Young cavities 
were most frequent $(46 \%)$ in the short length classes $(\mathrm{L}<4 \mathrm{~cm})$ and were overall significantly shorter than the other ones (One-Way ANOVA: $F_{1,233}=12.72$; $p<0.001$; average: $7.1 \pm 4.3 \mathrm{~cm})$. Mature cavities were most frequent in the seven following length classes $(4 \mathrm{~cm}<\mathrm{L}<18 \mathrm{~cm})$. Only few cavities measured more than $18 \mathrm{~cm}$. Among these longer cavities, inhabited and formerly inhabited cavities represented 7 out of 16 cavities. Indeed inhabited cavities were overall significantly longer than other types of cavities (One-Way ANOVA: $\mathrm{F}_{1,233}=$ $35.61 ; p<0.001 ; 14.1 \pm 7.0 \mathrm{~cm}$ versus $8.8 \pm 5.5 \mathrm{~cm})$.

\section{Location of the different cavity types on the branches}

Fig. 3 A, B, C and D illustrates the pattern of branch growth in diameter and the distribution of cavity types according to distance from the apex. Diameter remained constant at about $7 \mathrm{~mm}$ for the first $10 \mathrm{~cm}$ from the branch apex, then from $10 \mathrm{~cm}$ to $60 \mathrm{~cm}$ from the apex the diameter progressively increased to about $12 \mathrm{~mm}$. Finally from $60 \mathrm{~cm}$ to $130 \mathrm{~cm}$ the branch diameter remained constant at about $12 \mathrm{~mm}$.

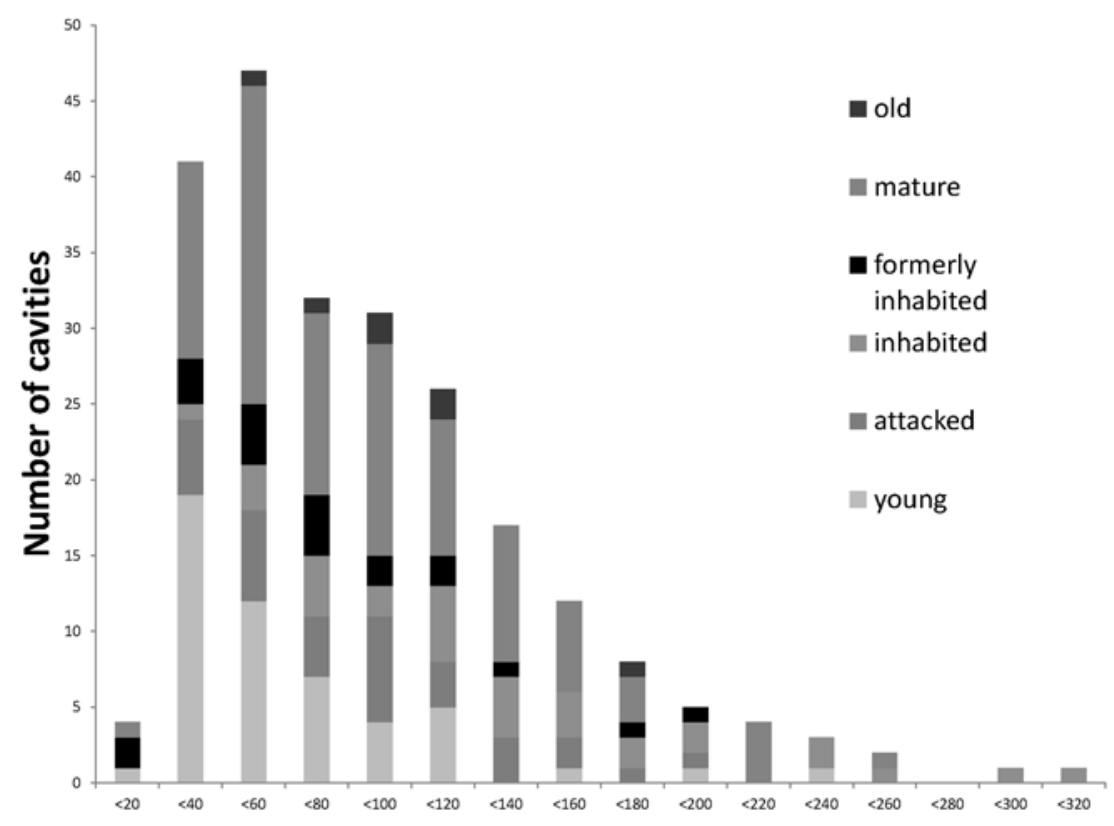

Cavity length classes

Fig. 2. Cavity length as a function of cavity type. Inhabited cavities are longer than average. 
Young cavities (empty or attacked by insect larvae) seem to constitute a homogeneous class. They were mainly concentrated in the first portion up to $10 \mathrm{~cm}$ from the apex (respectively 55 and $56 \%$ of them), but also in the second portion up to $20 \mathrm{~cm}$ and they were present, though in lower numbers, up to $40 \mathrm{~cm}$ from the apex (respectively $94 \%$ of intact ones and $86 \%$ of attacked ones were located less $40 \mathrm{~cm}$ from the apex). They were significantly closer to the apex than other cavity types (One-Way ANOVA: $\mathrm{F}_{1,221}=32.37$; $p<0.001)$. As a result, branch diameter at the level of young cavities was on average smaller than for other cavity types (One-Way ANOVA: $\mathrm{F}_{1,237}=$ 48.91; $p<0.001)$,
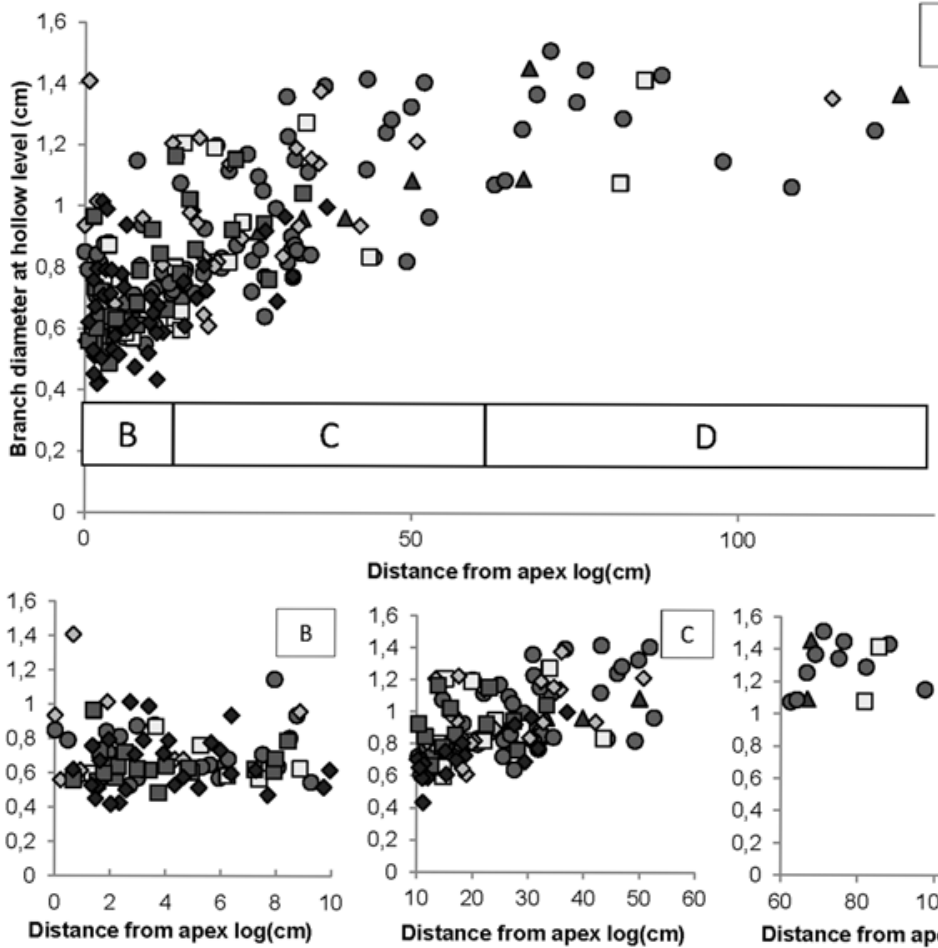

A

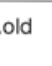

Omature

口formerly inhabited

৩inhabited

口young

attacked

•young
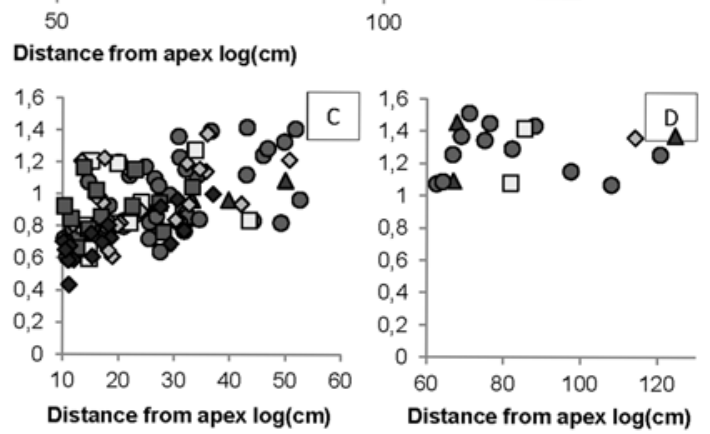

Fig. 3. A. Distance of the different types of cavities from the apex and branch diameter. B, C \& D: Detailed views of portions of graph A. Note that young cavities are only observed up to $40 \mathrm{~cm}$ from the apex and inhabited cavities are mainly observed up to $50 \mathrm{~cm}$ from the apex. 
Inhabited cavities and formerly inhabited cavities seem to form a second homogeneous class. They were present from the apical internode and concentrated in the first $35 \mathrm{~cm}$ from the apex although some were observed further away from the apex.

Mature cavities seem to constitute a third class. They were observed at all distances from the apex.

Finally only few cavities were in the process of closing due to secondary growth and they were located from $26 \mathrm{~cm}$ from the apex to $68 \mathrm{~cm}$ from the apex. Statistically, mature and old cavities were grouped as the furthest from the apex (One-Way ANOVA: $\mathrm{F}_{4,218}=13.74 ; p<0.001$ ).

The young cavities (intact and attacked) were mainly the most apical cavity when the branches presented more than one cavity. Young cavities attacked by insect larvae were frequent at the most apical internode; they represented $33 \%$ of the cavities at this internode. On the other hand old cavities were observed only from the fourth to the eleventh internode from the branch apex. Mature cavities were the most common for all the ranks, and they were observed up to the eleventh internode. Inhabited cavities were only observed in the four apical internodes, with a peak frequency at the third internode ( $50 \%$ of the inhabited cavities were located on the third internode). When a single cavity was noted for a branch, the cavity was in $67 \%$ of the cases a young cavity (intact or attacked).

\section{Ant species present within cavities}

Four ant genera were observed within the cavities of F. subpisocarpa branches: Crematogaster (Myrmicinae), Myrmica (Myrmicinae), Technomyrmex (Dolichorinae) and Prenolepis (Formicinae). On the six trees presenting inhabited cavities, 32 inhabited cavities were observed on 21 branches. Crematogaster ants occupied 25 cavities (78\% of the cavities), the three others genera occupied each two cavities. For the six branches presenting more than one occupied cavity (five branches with two occupied cavities and one with three), all were occupied by Crematogaster. One structure was shared by two species (Crematogaster sp. and Prenolepis sp.). This was in one of the few naturally open cavities, and ants from the two genera were living on each side of the open structure. The branches from trees 07 and 08 (Table 1) presented only one inhabited cavity each and the ants belonged both to 
genus Technomyrmex. All other trees hosted a mix of Crematogaster ants and other genera.

\section{Patterns of ant presence}

When Crematogaster ants were present, workers were observed in all the inhabited structures and their number ranged from eight to 320 individuals. Larvae and pupae were present in 10 of the 25 occupied cavities (40\%), winged Crematogaster adults in nine of them (36\%) and queens in four (16\%). In the Prenolepis inhabited cavities, the nest containing most workers (25 individuals) also contained larvae and pupae. The second one was the one shared with Crematogaster ants and sheltered only workers (16 individuals). One of the two cavities containing Technomyrmex contained 135 workers, nine queens, 51 pupae, 36 larvae but no winged adults, and the second one contained 37 workers, two queens, six pupae, three larvae and seven winged adults. Finally the two cavities inhabited by Myrmica ants presented fewer workers than for the other species (nine and 12 individuals), no winged males and both of them had two queens and winged females. In four cavities inhabited by Crematogaster, other ant species were also collected. In tree 05, all inhabited cavities contained Crematogaster ants but in two of them Technomyrmex ants were also collected inside the nest (one and six individuals). Moreover one Prenolepis ant was found in a cavity on tree 01 , and this tree sheltered a sampled Prenolepis nest. Similarly, a Myrmica ant was found in a cavity inhabited by Crematogaster in tree 06, and that tree presented a cavity inhabited by Myrmica ants.

Crematogaster ants tended to inhabit longer and wider cavities than the other species (Fig. 4). Nevertheless, cavity diameter was independent of
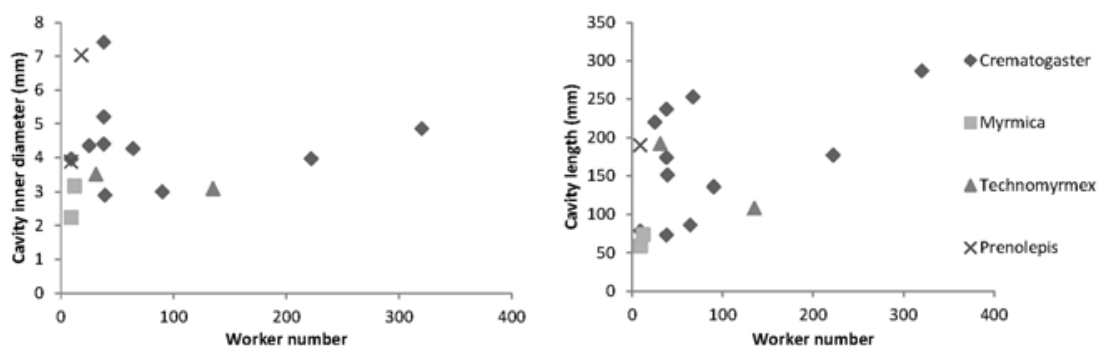

Fig.4. Worker distribution according to cavity inner diameter (left) and to cavity length (right). Cavity diameter was measured at its mid point. Cavity diameter was independent of colony size. 
branch diameter: all Crematogaster ants were living in similar-width nests. The ants of this genus were occupying cavities from very close to the apex to more than one meter away from the apex (Fig. 4).

\section{Presence of other insects within cavities}

Fig wasps (captured by ants) were found in six inhabited cavities. Both Technomyrmex nests contained fig wasps (the first one, one F. subpisocarpa female pollinating wasp (Platyscapa ischiana) and three wingless males and the second one, one P. ischiana female wasp and two female non-pollinating fig-wasps of genus Sycoscapter). Then one Crematogaster cavity contained two non-pollinatingfemale wasps Otitesella ako (agenus whose precise oviposition period is species dependent, Compton 1993) while a second one contained a female non-pollinating fig wasp from genus Sycoscapter (a genus ovipositing after the pollinator in the figdevelopment sequence; Tzenget al.2008). Finally in the cavity inhabited by two ant species two female Platyscapa ischiana were collected and 18 female Sycoscapter sp. The antennae and the ovipositors of the collected fig wasps had been cut off by the ants.

A scale insect (Hemiptera: Coccoidea) and an aphid (Hemiptera: Aphidoidea) were found in two distinct Crematogaster inhabited cavities. The larvae attackingyoung cavities were Coleopteran larvae. Finally, Curculionidae beetles (Coleoptera) were often observed on F. subpisocarpa branches (Bain, pers. obs.).

\section{Correlation between presence of ants and presence of hemipterans}

We frequently observed sap sucking insects on different vegetative parts of $F$. subpisocarpa. Scale insects were often observed on leaves and in shelters built by Crematogaster ants between figs or at the base of ramifications, but also occurred on figs, while aphids were almost only observed on figs. Ants were observed tending both scale insects and aphids. Ants, coccids and aphids were observed on the branches.

In the set of 110 branches that were specifically monitored for ant and hemipteran presences, ants were observed on 24 branches and were distributed into 3 genera: Crematogaster (23 branches), Prenolepis (1 branch, on which Crematogaster was also present) and Myrmica (1 branch). The branch presenting Myrmica ants presented no hemipterans, so in all cases when ants 
were associated with hemipterans, Crematogaster ants were present on the branch.

We observed a correlation between the presence of Crematogaster ants and the presence of hemipterans on the 110 branches examined. Indeed, Crematogaster were observed on 23 branches and were associated with hemipterans in 20 cases, while hemipterans were present on 33 branches (correlation test on the cumulative observations: Kendall tau=0.940, $\mathrm{p}<0.001)$.

Aphids were mainly observed on figs (10 cases, often in association with coccids) as opposed to on the leaves ( 3 cases out of which two corresponded to winged individuals). In 8 out of 10 cases aphids were observed on figs, they were associated with Crematogaster ants. Coccids seemed to be much less specialised as the coccids were observed only in the cavities ( 2 branches), only on the leaves ( 12 branches), or both in the cavities and on the leaves ( 2 cases), on leaves and figs ( 4 cases) and in all three locations ( 4 cases).

\section{Comparison with cavities observed in herbarium samples}

Cavities similar to those observed in Taiwan were found in all herbarium samples from typical Ficus subpisocarpa Gagnep. collected in Japan and Vietnam, from Ficus subpisocarpa Gagnep. subsp. pubipoda C.C. Berg collected in Thailand and from Ficus geniculata Kurz collected in Vietnam and Thailand.

\section{DISCUSSION}

While the presence of a central cavity within the branches of fig trees is quite common, we demonstrated here that cavity traits in F. subpisocarpa allow a series of ant species to inhabit these cavities. After an analysis of occurrence of branch cavities in dioecious and monoecious fig species, we will examine how this trait may favor myrmecophytism, in conjunction with the different food sources exploited by ants on different Ficus species.

The presence of hollow internodes is well known though hardly investigated in Ficus. It is frequent in dioecious species as exemplified by the reference in the species name to fistulose branches in Ficus fistulosa Reinw. ex Blume, Ficus fistulosa Koord (=F. congesta Roxb.) and Ficus fistulosa Kurz (=Ficus schwarzii Koord). Corner (1967) stated that, in F. cristobalensis, twigs are 10-20 mm thick, with indistinct internodes and the wide pith is often hol- 
lowed by ants. Nevertheless, quantitative reports on the presence of hollow internodes in live plant material and their use by ants in Ficus are basically lacking. We provide here a first report on the presence of hollow internodes in a monoecious fig species and on the colonization of these hollow internodes by ants. Ficus subpisocarpa presents hollow internodes all over its range, and hollow internodes are also present in its close relative F. geniculata. In F. subpisocarpa these hollow internodes are used by ants that make entry/exit holes to access the cavities. These occupied hollow internodes are located close to the branch apices.

While hollow internodes could be rather frequent in dioecious figs, they seem to be less frequent in monoecious figs of subgenus Urostigma. However, a characteristic trait of subsection Urostigma (about 23 species) to which $F$. subpisocarpa belongs, isintermittentgrowth, usually seasonal and accompanied with deciduousness (Berg \& Corner 2005), as opposed to continuous growth in many subgenus Urostigma species. Fast growing plants often produce twigs presenting more pith than species producing slowly growing twigs. We suggest that quick growth of the twig associated with intermittent growth is a major feature at the origin of the hollow internodes in F. subpisocarpa.

Hollow internodes are a feature that may facilitate the evolution of myrmecophytism. Myrmecophytism also involves producing food (nectar, food bodies) that will stabilize the ant nests. Ficus provide ants with an access to fig-wasps, pollinators and parasites. While fig-pollinating wasps are present on the trees for short spells of time, at fig receptivity and at wasp emergence, parasites are present on the fig surfaces for longer periods of time. Schatz $e t$ al. (2008) suggested that cauliflory, the abundant production of figs on short specialized branches, allowed easier patrolling of figs by ants and thus could be conceived as a way of stabilizing ant nests in a tree and getting protection against parasitic wasps. While cauliflory is little represented in subgenus Urostigma, F. subpisocarpa as a number of species of subsection Urostigma is cauliflorous, producing numerous clusters of small figs on the branches. The species also fruits frequently producing $2-4$ fig crops a year and a crop may ripen over a period of 3 weeks (Corlett 2006, Bain pers. obs.), two characters that increase the number and length of periods when fig-wasps can be used as a food source exploited by ants. This is all the more true as the ants, beyond pollinators, collected non-pollinating fig wasps ovipositing before 
(Otitesella) and after (Sycoscapter) the pollinators, thus extending the period during which a crop provides food for ants. Intermittent growth, cauliflory, frequent fruiting and prolonged fig maturation period may constitute a set of characters of F. subpisocarpa that facilitate the establishment of a strong interaction with ants.

Nevertheless, despite these features, in monoecious figs, fig wasps may still not provide sufficient resources for ants to establish stable nests within fig branches. We hypothesize that beyond capturing fig wasps during their presence on figs (oviposition period and the period of emergence from figs), ants may also depend on hemipterans when fig wasps are less abundant. Several of our observations support this hypothesis. First, we observed hemipterans more frequently on branches colonized by ants, and we observed captured hemipterans (scale insects and aphids) within cavities inhabited by ants. Hemipterans present in $F$. subpisocarpa could thus constitute a regular source of both honeydew and prey. Ant-hemipterans interactions have previously been reported in two African monoecious fig species (Dejean et al. 1997; Zachariades et al. 2009), but we provide here the first observations of predation by ants in the fig context. More detailed studies will be required to investigate the contribution of hemipterans in the diet and maintenance of ants on fig trees. Second, fig wasps were found in six nests of Crematogaster, Technomyrmex and Prenolepis ants. On two dioecious fig species, ants (especially Crematogaster species) are also known to feed on fig wasps (Schatz et al. 2008), and to constitute strong non-pollinating wasp repellents (Schatz \& Hossaert-McKey 2003). Non-pollinating fig wasps with cut ovipositors discovered in F. subpisocarpa cavities suggests that Crematogaster ants capture them while they are ovipositing with their ovipositor inserted through the fig wall, as observed on dioecious figs (Schatz et al. 2006, 2008). More detailed studies are required to determine the impact of ants on fig wasps population. Available data suggests that exploitation of both hemipterans and fig wasps as two permanent food sources may be sufficient to explain continuous ant presence in monoecious fig trees.

We also observed on the monoecious F. subpisocarpa that ants seem to predate more non-pollinating fig wasps than pollinating ones. This observation suggests a positive role of ants for the fig-fig wasp mutualism, acting here as indirect mutualists (Dawkins \& Krebs 1979; Bronstein 1991; Schatzet al. 2006, 
2008). Even if the impact of ants on the populations of hemipterans and fig wasps needs to be investigated in detail, we may surmise that the monoecious F. subpisocarpa may be selected to provide shelters for ant nests. Nevertheless, the caulinary cavities in which the ants nested are hardly sophisticated and the dwellers need to excavate the inner pith to be able to inhabit them and they have to create openings to gain access. Thus, the hollow structures of $F$. subpisocarpa branches sheltering ants should be considered as potential domatia precursors according to current terminology (Webber et al. 2007). In addition, the predominance of Crematogaster among ants inhabiting this fig species may appear as a trend towards specialization in this ant-plant interaction. Because we observed similar structures in the related Ficus geniculata, we may infer that the current level of association is quite old and that selective pressures are not strong enough to lead to the evolution of more specialized structures such as in the Acacia or Macaranga genera. Such results certainly incite further investigation about insects-fig interactions, and reinforce the status of fig trees as supporting complex networks of interactions (Compton and Robertson 1988; Zachariades 1994; Schatz \& Hossaert-McKey 2003; Schatz et al. 2006, 2010).

\section{ACKNOWLEDGMENTS}

Many thanks to B. Di Giusto and Florian Massip for technical help in the field. This study was supported by ANR grant Biofig.

\section{REFERENCES}

Bascompte, J. 2009. Disentangling the web of life. Science 325:416-419.

Bascompte, J. \& P. Jordano. 2007. Plant-animal mutualistic networks: the architecture of biodiversity. Annual Review of Ecology and Systematics 38:567-593.

Berg, C.C. \& E.J.H. Corner. 2005. Moraceae (Ficus). In: Flora Malesiana (H.P. Nooteboom,

Ed), National Herbarium Nederland, Leiden

Bolton, B. 1994. Identification guide to the ant genera of the world. Harvard University Press, Cambridge.

Bouček, Z., A. Watsham \& J.T. Wiebes. 1981. The fig wasp fauna of Ficus thonningii (Hymenoptera, chalcidoidea). Tijdschrif voor Entomologie 124:149-233.

Bronstein, J.L. 1991. The non-pollinating wasp fauna of Ficus pertusa: exploitation of a mutualism? Oikos 61:175-186.

Bronstein, J.L. 2001. The exploitation of mutualisms. Ecology Letters 4:277-287. 
Cavender-Bares, J. \& K.H. Kozak, P.V.A. Fine \& S.W. Kembel. 2009. The merging of community ecology and phylogenetic biology. Ecology Letters 12:693-715.

Chen, Y. R. \& W.C. Chuang \& W.J. Wu 1999. Chalcid wasps on Ficus microcarpa L. in Taiwan (Hymenoptera: Chalcidoidea). Journal of Taiwan Museum 52:39-79.

Compton, S.G. 1993. One way to be a fig. African Entomology 1:151-158.

Compton, S.G. \& H.G. Robertson. 1988. Complex Interactions Between Mutualisms: Ants Tending Homopterans Protect Fig Seeds and Pollinators. Ecology 69:1302-1305.

Cruaud, A., R. Jabbour-Zahab, G. Genson, C. Cruaud, A. Couloux, F. Kjellberg, S. van Noort \& J.Y.Rasplus. 2009. Laying the foundations for a new classification of Agaonidae (Hymenoptera: Chalcidoidea), a multilocus phylogenetic approach. Cladistics 25:129.

Davidson, D.W. \& B.L. Fisher. 1991. Symbiosis of ants with Cecropia as a function of light regime. In: Ant-plant interactions (C.R. Huxley \& D.F. Eds.), Oxford University Press, Oxford, pp. 289-309.

Davidson, D.W. \& D. McKey. 1993. The evolutionary ecology of symbiotic ant-plant relationships. Journal of Hymenoptera Research 2:13-83.

Dawkins, R. \& J.R. Krebs. 1979. Arms races between and within species. Proceedings of the Royal Society London B 205:489-511.

Dejean, A., T. Bourgoin \& M. Gibernau. 1997. Ant species that protect figs against other ants: Result of territoriality induced by a mutualistic homopteran. Ecoscience 4:446-453.

Dunn, D.W., S.T.Segar, J. Ridley, R. Chan, R.H. Crozier, D.W. Yu \& J.M. Cook. 2008. A role for parasites in stabilising the fig-pollinator mutualism. PLoS Biology 6:490-496.

Fiala, B.,H. Grunsky, U.Maschwitz, K.E.Linsenmair. 1994. Diversity of ant-plant interactions: protective efficacy in Macaranga species with different degrees of ant association. Oecologia 97:186-192.

Fortuna, M.A.\&J.Bascompte. 2006. Habitat loss and the structure of plant-animal mutualistic networks. Ecology Letters 9:281-286.

Gaume, L., D. McKey D \& S. Terrin. 1998. Ant-plant-homopteran mutualism: how the third partner affects the interaction between a plant-specialist ant and its myrmecophyte host. Proceedings of the Royal Society B 265:569-575.

Giladi, I. 2006. Choosing benefits or partners: a review of the evidence for the evolution of myrmecochory. Oikos 112:481-492.

Grison, L., A.A. Edwards \& M. Hossaert-McKey. 1999. Interspecies variation in floral fragrances emitted by tropical Ficus species. Phytochemistry 52:1293-1299.

Heil, M. 2007. Indirect defence via tritrophic interactions. New Phytologist 178:41-61.

Heil, M. \& D. McKey. 2003. Protective ant-plant interactions as model systems in ecological and evolutionary research. Annual Review of Ecology, Evolution and Systematics 34:425-453.

Ings, T.C., J.M. Montoya, J. Bascompte, N. Bluthgen, L. Brown, C.F. Dormann, F. Edwards, D. Figueroa, U. Jacob, J.I. Jones, R.B. Lauridsen, M.E. Ledger, H.M. Lewis, J.M. Olesen, F.J.F. van Veen, P.H. Warren \& G. Woodward. 2009. Ecological networks - beyond food web. Journal of Animal Ecology 78:253-269. 
Kaufmann, S., D.B. McKey, M. Hossaert-McKey \& C.C. Horvitz. 1991. Adaptations for a two-phase seed dispersal system involving vertebrates and ants in a hemiepiphytic fig (Ficus microcarpa: Moraceae). American Journal of Botany 78:971-977.

Kerdelhué, C. \& J.Y. Rasplus. 1996. The evolution of dioecy among Ficus (Moraceae): an alternative hypothesis involving non-pollinating wasp pressure on the fig-pollinator mutualism. Oikos 77:163-166.

Kjellberg, F., E. Jousselin, M. Hossaert-McKey \& J.Y. Rasplus. 2005. Biology, ecology, and evolution of fig-pollinating wasps (Chalcidoidea, Agaonidae). In: Biology, ecology and evolution of gall-inducing arthropods (A. Raman, W. Schaefer \& T.M. Withers Eds), Science Publishers, Inc., Enfield (NH) USA Plymouth (UK), pp. 539-572

Lach, L., C.L. Parr \& K. Abbott. 2009. Ant Ecology. Oxford University Press, Oxford.

Laman, T.G. 1995. Ficus stupenda germination and seedling establishment in a Bornean rain forest canopy. Ecology 76:2617-2626.

Laman, T.G. 1996. The impact of seed harvesting ants(Pheidolesp. nov.) on Ficus establishment in the canopy. Biotropica 28:777-781.

Lin, C.-C., W.-J. Wu. 2003. The ant fauna of Taiwan (Hymenoptera: Formicidae), with the keys to subfamilies and genera. Annal of the National Taiwan Museum 45:5-69.

Maschwitz, U., B. Fiala, L.G. Saw, Y. Norma-Rashid, H.I. Azarae. 1994. Ficus obscura var. borneensis (Moraceae), a new non-specific ant-plant from Malaysia. The Malayan Nature Journal 47:409-416.

McKey, D. 1984. Interaction of the ant-plant Leonardoxa africana (Caesalpiniaceae) with its obligate inhabitants in a rainforest in Cameroon. Biotropica 16:81-99.

Proffit, M., B.Schatz, J.M. Bessière, C. Chen, C. Soler \& M. Hossaert-McKey. 2008. Signaling receptivity: Comparison of the emission of volatile compounds by figs of Ficus hispida before, during and after the phase of receptivity to pollinators. Symbiosis 45:15-24.

Ranganathan, Y., M. Ghara \& R.M. Borges. 2010. Temporal associations in fig-wasp-ant interactions: diel and phenological patterns. Entomologia Experimentalis et Applicata 137:50-61.

Speight, M.R., M.D. Hunter \& A.D. Watt. 2008. Ecology of insects, Second Edition edn. Wiley Blackwell Publications.

Ranganathan, Y. \& R.M. Borges. 2009. Predatory and trophobiont-tending ants respond differently to fig and fig wasp volatiles. Animal Behaviour 77:1539-1545.

Rico-Gray, V. \& P.S. Oliveira. 2007. The ecology and evolution of ant-plant interactions, The University of Chicago Press, Chicago

Risch, S., M. McClure M, J. Vandermeer J \&S. Waltz. 1977. Mutualism between three species of tropical Piper (Piperaceae) and their inhabitants. American Midland Naturalist 98:433-444

Roberts, J.T. \& E.R. Heithaus. 1986. Ants rearrange the vertebrate-generated seed shadow of a neotropical fig tree. Ecology 67:1046-1051.

Rosumek, F., F.A.O. Oliveira, F. de S. Neves, N.P.D. Barbosa, L. Diniz, Y. Oki, F. Pezzini, G.W. Fernandes \& T. Cornelissen. 2009. Ants on plants: a meta-analysis of the role of ants as plant biotic defenses. Oecologia 160:537-549. 
Schatz, B. \& M. Hossaert-McKey. 2003. Interactions of the ant Crematogaster scutellaris with the fig/fig wasp mutualism. Ecological Entomology 28:359-368.

Schatz, B., F. Kjellberg, S. Nyawa \& M. Hossaert-McKey. 2008. Fig wasps: a staple food for ants on Ficus. Biotropica 40:190-195.

Schatz B., M. Proffit, B.V. Rakhi, R.M. Borges \& M. Hossaert-McKey. 2006. Complex interactions on fig trees: ants capturing parasitic wasps as possible indirect mutualists of the fig-fig wasp interaction. Oikos 113:344-352.

Shanahan, M., R.D. Harrison, R. Yamuna, W. Boen \& I.W.B. Thornton. 2001. Colonization of an island volcano, Long Island, Papua New Guinea, and an emergent island, Motmot, in its caldera lake. V. Colonization by figs (Ficus spp.), their dispersers and pollinators. Journal of Biogeography 28:1365-1377.

Suarez, A.V., C. de Moraes \& A. Ippolito. 1998. Defense of Acacia collinsii by an obligate and non-obligate ant species: The significance of encroaching vegetation. Biotropica 30:480-482.

Tzeng, H.J., L.J. Tseng, C.H. Ou, K.C. Lu, F.Y. Lu, L.S. Chou. 2008. Confirmation of the parasitoid feeding habit in Sycoscapter, and their impact on pollinator abundance in Ficus formosana. Symbiosis 45:129-134.

van Noort, S. \& S.G. Compton. 1996. Convergent evolution of Agaonine and Sycoecine (Agaonidae, Chalcidoidea) head shape in response to the constraints of host fig morphology. Journal of Biogeography 23:415-424.

Vázquez, D.P., N. Blüthgen, L. Cagnolo \& N.P. Chacoff. 2009. Uniting pattern and process in plant-animal mutualistic networks: a review. Annals of Botany 103:1445-1457.

Webber, B.L., J. Moog, A.S.O. Curtis \& I.E. Woodrow. 2007. The diversity of ant-plant interactions in the rainforest understorey tree, Ryparosa (Achariaceae): food bodies, domatia, prostomata, and hemipteran trophobionts. Botanical Journal of the Linnean Society 154:353-371.

Wei, Z.D., Y.Q. Peng, L. XU \& D.R. Yang. 2005. Impact of Oecophylla smaragina on the percentage number of offspring of pollinator and non-pollinating wasps on Ficus racemosa. Zoological Research 26:386-390.

Weiblen, G. 2002. How to be a fig wasp? Annual Review of Entomology 47:299-330.

Zachariades, C., S.G. Compton \& B. Schatz. 2009. Honeydew as Danegeld? Ants (Hymenoptera: Formicidae) tending a honeydew-producing homopetran do not offer protection from its main natural enemies. Sociobiology 54 471-488.

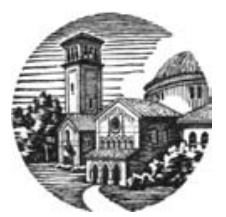

